\title{
ACEPTACIÓN Y MODIFICACIÓN DE LAS IDENTIDADES MIGRATORIAS
}

\author{
Sofía Alonso Díaz. Universidad de Huelva \\ Supervisado por: Miriam Hervas Torres. Departamento de Psicología de la Educación. Universidad de Huelva \\ Fecha de recepción: 24 de enero de 2014. \\ Fecha de revisión: 19 de marzo de 2014. \\ Fecha de aceptación: 11 de abril de 2014.
}

\section{Resumen}

El presente artículo trata sobre la forma en que las culturas autóctonas reciben y aceptan a las culturas migratorias. Habla sobre cómo afecta a la relación entre las culturas, y de qué modo la identidad de cada uno se ve alterada. Para ello se presenta los resultados de un estudio etnográfico en el que se analizaron los contextos escolares y sociales en los que se desarrollan las experiencias de los jóvenes marroquíes en Cataluña, España.

Principalmente se hace una descripción sobre los conceptos importante como identidad, que es el núcleo de este artículo. Como principal objetivo, se encuentra conocer el nivel de aceptación de las culturas migratorias en las culturas autóctonas y la capacidad de mantenimiento de identidad de las culturas migratorias.

Palabras Clave: Identidad, Aceptación, Inmigración

\begin{abstract}
This article discusses how indigenous cultures are accepted and migratory cultures. Talk about how it affects the relationship between cultures, and how the identity of each is altered. This results from an ethnographic study in which school and social contexts in which the experiences of young Moroccans in Catalonia, Spain are developed analyzed is presented.

Primarily a description of the important concepts of identity, which is the core of this article is. Main objective is to know the level of acceptance of migratory cultures of indigenous cultures and the ability to maintain identity of migrant cultures.
\end{abstract}

Keywords: identity, acceptance, Immigration

\section{Introducción}

La identidad étnica de un individuo como adscripción a una categoría étnica no resulta de una decisión que repose sobre una identificación sino más bien de un proceso de clasificación que le es exterior. Sin embargo, el concepto de pertenencia ayuda a explicar el hecho de que los individuos étnicamente categorizados puedan desarrollar 
un sentimiento de pertenencia a un mismo grupo, y que ello les pueda permitir, por ejemplo, crear redes de solidaridad o una red de institu- ciones y de asociaciones destinadas a defender sus intereses (M. Martiniello, 1994: 107). Ésta, es un fenómeno que surge de la dialéctica entre el individuo y la sociedad ( $P$ Berger y T. Luckmann, 1968: 65).

La identidad es uno de los fenómenos psicosociales que más se ve afectado por los procesos migratorios. No en vano, hoy día constituye ya una dimensión básica que complementa la integración económica, social y cultural con los inmigrados. La forma en que los individuos se piensan a sí mismos se ve sometida a tensiones específicas cuando ese pensamiento se pone en marcha en contextos en los que los grupos, los valores o las costumbres divergen de los que constituyen las referencias habituales (cercanas o íntimas). El conflicto de adaptación cultural que se vive entonces se conoce como aculturación, y una de las formas de estudiarlo es a través de las transformaciones que experimenta la identidad de los individuos implicados en el movimiento migratorio (Schwartz, Montgomery y Briones, 2006).

Por lo que investigar las relaciones que tienen con otros es crucial porque las identidades que desarrollan y su propio sentido de quiénes son, dependen, no sólo de las interacciones que tienen en su vida privada, sino con todo el contexto que le rodea (Appiah, 2006; Taylor et al., 1994).

Para ello las identidades que se van a estudiar son la identidad en España, ya que aunque en su pasado había muchas cosas que los unía, en la actualidad siguen un patrón de cultura muy diferente (M. Chakor, 2003). Y todo ello se hará con el objetivo de conocer el nivel de aceptación de las culturas migratorias en las culturas autóctonas y la capacidad de mantenimiento de identidad de las culturas migratorias.

\section{Metodología}

Los datos analizados proceden de una etnografía escolar y comunitaria. Se encuentra dentro de un proyecto de investigación más amplio sobre familias inmigrantes y condiciones de integración social y escolar de sus hijos e hijas.

La etnografía se centró en 31 chicos y 18 chicas marroquíes de edades comprendidas entre los 12 y 16 años, estudiantes de un instituto de educación secundaria, y en sus familias.

En las cuales 12 de ellos eran padres y jóvenes de familias, 6 profesores, 4 dedicados a la gestión administrativa y por último 10 miembros de la comunidad local.

En el estudio se aplicaron técnicas cualitativas (observación participante, entrevistas informales, semi-estructuradas y estructuradas - que se realizaron entre el profesorado en la escuela y entre los jóvenes y familias en su mayoría fuera de ella -, reconstrucción de historias migratorias individuales y familiares, técnicas biográficas, análisis documental, etc.) y cuantitativas (tratamiento de expedientes académicos individuales, de sanciones disciplinarias y de resultados académicos de cada estudiante y en relación a su grupo clase) en todos los ámbitos de observación señalados y de forma simultánea. El diario de campo fue el instrumento clave para registrar el acontecer de la cotidianeidad tanto dentro y fuera del aula, en la escuela como en el barrio.

El trabajo de campo se desarrolló desde el curso 1998-99 hasta el año 2004-05. 


\section{Resultados}

Tablas de porcentaje del mantenimiento de identidad y sobre puntuación aceptación en la comunidad receptora.

\begin{tabular}{|l|l|}
\hline Mantenimiento de la identidad & \multicolumn{2}{|l}{} \\
\hline Sí completamente & $50 \%$ \\
\hline No & $0 \%$ \\
\hline Mayormente la cultura de origen & $40 \%$ \\
\hline Mayormente la cultura de los autóctonos & $10 \%$ \\
\hline
\end{tabular}

Tabla1: Mantenimiento de las identidades culturales.

\begin{tabular}{|l|l|l|}
\hline & Aceptación & No aceptación \\
\hline Autóctonos & $90 \%$ & $10 \%$ \\
\hline $\begin{array}{l}\text { Inmigrantes (percepción de } \\
\text { aceptación de los demás) }\end{array}$ & $40 \%$ & $60 \%$ \\
\hline
\end{tabular}

Tabla2: Aceptación y percepción de ella.

Midiendo el mantenimiento de las identidades en la cultura migratoria, puede decirse que la mitad del porcentaje se reparte sólo en los inmigrantes que mantienen su identidad, su cultura y sus costumbres muy arraigadas (75\%), en cuanto a los que no la mantienen en absoluto no se ha detectado ningún sujeto en esta investigación. por otro lado el otro $50 \%$ restante se reparte entre los que mayormente mantienen su cultura de origen $(40 \%)$ y por otro lado los que mayormente han obtenido una nueva identidad mayormente de la nueva cultura (10\%).

Evaluando la aceptación de los habitantes autóctonos, puede decirse que las gran mayoría (90\%) acepta con total normalidad a simple vista, la relación intercultural, por el contrario una minoría (1\%) de forma rotunda niega esta relación.

Respecto a la percepción que tienen los marroquíes sobre la aceptación de los españoles, el $40 \%$ cree en la aceptación totalmente sincera de los autóctonos, mientras que el $60 \%$ no lo cree, y si lo hace, le queda un ápice de duda.

\section{Discusión}

Como se ha explicado en la introducción, los inmigrantes pasan por un proceso en el cual su identidad se ve amenaza, ya que el hecho de comenzar en una cultura diferente, donde incluso algunas costumbres son opuestas, donde no se sabe cómo pueden recibirlos, les influye en la trasformación y construcción de una nueva identidad. Aunque ese proceso sea extraño para ellos, y se encuentres desubicados, los resultados de este estudio han sugerido unos datos muy diferentes a lo esperado, ya que de forma general los inmigrantes marroquíes, mantienen una identidad muy arraigada por lo que no la modifican, y siguen con sus costumbres, patrones de conducta y su cultura de origen, dentro de sus posibilidades. 
Todo esto puede ocurrir ya que cuando llegan a otro lugar, se forma como un grupo muy cohesionado para defenderse de otros, y globalmente se apiñan para no perder nada de sus costumbres. Todo esto tiene sin duda su más profunda influencia de su religión, aunque no es ahora cuando toca hablar de este tema.

También existen aquellos que absorben todo lo posible de la nueva cultura e intenta integrarse de forma muy completa, aunque esto son los mínimos. También predominan aquellos que aunque sin dejar su cultura y costumbres de lado, se integran en el nuevo sistema.

Gran parte de la identidad se pierde, pero construyen otra, ya que la identidad no sólo se pierde con el cambio de territorio, sino con cualquier cambio más allá de lo común. Pero cuando se menciona el perder la identidad, no se hace alusión a la pérdida total de ésta, sino a la flexibilidad y a la aceptación de absorber más allá de lo que antes se absorbía.

En cuanto a la postura que adquieren los autóctonos con los inmigrantes, en los resultados se demuestra, que la gran mayoría los acepta, y que ellos mismo se ven aceptados por la mayoría.

La multiculturalidad cada día es más común en todos los territorios, por lo que las personas ya han adquirido una postura más actualizada. Actualmente la inmigración que se produce en la mayoría de los países, y en este caso, España, crea un concepto diferente de cultura arraigada ya que como dice Calvo (1995:13), "la sociedad española es muy heterogénea a nivel de sistema de valores, configuraciones mentales, orientaciones políticas y conciencias étnicas colectivas. Es, además una sociedad multicultural y multiétnica y lo será más en el futuro, no sólo por la diversidad autonómica, sino por la génesis de otras culturas y subculturas minoritarias".

Como conclusión puede decirse que aunque las cosas poco a poco estén cambiando, y las culturas estén aceptando su interrelación, queda todavía mucho que trabajar, ya que hay un porcentaje de personas y grupos sociales que les cuesta asimilar y aceptar esta situación. Suelen ser personas muy territoriales y nacionalistas, pero poco a poco y con el peso de la mayoría las personas tendrán que acostumbrarse.

\section{Referencias}

Appiah, K. A. (2006). The Politics of Identity. Daedalus. Journal of the American Academy of Arts and Sciences, 15-22.

BERGER, P. y LUCKMAN, T. (1968): La construcción social de la realidad. Buenos Aires, Amorrortu Editores.

Calvo Buezas, T. (1995). “Aprender a vivir la diferencia”. En Vela Mayor nº 5 (13-18).

CHAKOR, M. (2003), España y Marruecos de la prehistoria al siglo XX, inédito.

Duranti, A. (1994). From grammar to politics. Linguistic anthropology in a Western Samoan village. University of California Press. 
Duranti, A. (2000). Antropología Lingüística. Madrid: Cambridge University Press (Distribuido por Ediciones Akal, S.A.)

MARTINIELLO, M. (1994): «Élites et leaders ethniques: entre mobilité sociale et structuration communautaire», en Revue Internationale d'Action Communautaire $n^{\circ} 31 / 71$, pp. 105-117.

Schwartz, S.J., Montgomery, M.J., Briones, E. (2006) "The Role of Identity in Acculturation among Immigrant People: Theoretical Propositions, Empirical Questions, and Applied Recommendations", Human Development, 49:130. 